\title{
O cinema e
}

\section{"novas"}

\section{tecnologias: o espetáculo continua}

\section{RESUMO}

0 presente texto faz uma reflexão sobre o impacto das novas tecnologias no cinema contemporâneo, no sentido de mostrar que elas reativam antigas questões quanto à representação cinematográfica e que, apesar das transformações na maneira de fazer e de ver os filmes, a essência como foi concebido 0 espetáculo cinematográfico continua intacta.

\section{ABSTRACT \\ This article reflects upon the impact of new technologies in contemporaneous cinema in order to show that those technologies awake old questions about cinematographic representation - but that, in spite of the changes in the manner of making and watching movies, the essence of cinema remains the same.}

\section{PALAVRAS-CHAVE (KEY WORDS)}

- Cinema (Film)

- Novas tecnologias (New technologies)

- Representação cinematográfica (Cinematographic representation)

\section{Cristiane Freitas}

Dra. em Sociologia pela Université de Paris V - Sorbonne
O CINEMA SE encontra num momento de mutação onde transformações importantes estão acontecendo no que se refere até mesmo à natureza do espetáculo cinematográfico. Durante o curso de sua história centenária, o cinema passou por muitas inovações importantes como, por exemplo, do cinema mudo ao falado, do preto e branco ao colorido, da tela comum à gigante. Tais fases se desenvolveram intercaladas por longos períodos de estabilidade. Em contrapartida, a evolução tecnológica atual é mais rápida e desordenada que as precedentes, colocando o cinema no meio de um sistema cultural complexo e instaurando uma sinergia entre a produção cinematográfica, as telecomunicações, - cabo e a informática, o que afeta a elaboração das imagens, seus modos de produção e de distribuição. Nosso objetivo está em tentar compreender o que tais avanços técnicos acarretaram na representação cinematográfica, bem como o impacto dessas mutações no cinema contemporâneo, na forma de fazer e de ver os filmes.

O cinema é a mais tecnológica de todas as artes, constituindo-se num inventário de materiais e de técnicas que são empregadas a favor das diferentes formas de efeitos especiais, os quais remontam as origens do cinema com Méliès e os irmãos Lumière. $O$ efeito especial é, portanto, o meio pelo qual o impossível e o mágico se tornam visíveis, participando regularmente do processo de formação das identidades fílmicas. Nesse sentido, as técnicas cinematográficas nunca deixaram de evoluir e, recentemente, elas 
se aglutinaram em torno do computador e sobretudo da linguagem digital.

Essa inovação colocou mais uma vez em questão a capacidade mimética das imagens cinematográficas. Durante muito tempo, a representação fílmica foi tida como mediadora, permitindo que uma coisa que não estivesse aqui no momento (a realidade) voltasse sob uma outra forma (a imagem). Com o aprimoramento do debate sobre a representação, levando-se em conta o aspecto subjetivo das imagens e relacionando-as com a fusão existente entre a complexidade do cinema e a sua técnica, o cinema é considerado, hoje em dia, como uma interação obtida entre a construção de um produto originado de condições materiais específicas e a autonomia do filme como produção artística composta de recursos técnicos (o enquadramento, a luz, a fotografia, o som) que dão um significado particular à imagem.

Não vamos fazer aqui uma análise teórica dos defensores e dos detratores do que essas mudanças acarretaram no mundo do cinema, mas sim tentar mostrar que as tecnologias recentes, quaisquer que sejam as suas formas, não fazem outra coisa que reativar antigas questões em torno da representação cinematográfica.

A informática, que afirma a sua presença em todos os domínios científicos, é moldada por algo de misterioso que nos remete "ao tudo é possível" da ciência e à vontade de impulsionar a técnica até os seus limites e, assim, superá-la. Sob a aura dos efeitos especiais, o computador recorre à mágica para proporcionar todo tipo de sensação no espectador. Foi nos anos 70 que a informática fez sua estréia no cinema, quando estavam no apogeu os filmes de ficção científica baseados no imaginário ligado à conquista e à exploração do espaço, especificamente com Star Wars (George Lucas, 1977) e a simulação digital da estrela negra, filme que será seguido por outros como Star Trek, The Movie (Robert Wise, 1979) e Alien (Ridley Scott, 1979).

No começo dos anos 80 , a Walt
Disney se lançará na produção de Tron (Steven Lisberg, 1982), filme high-tech que se tornará um fetiche para os amadores do gênero e cuja ação se desenvolve no coração de um video game, promovendo assim o encontro do cinema com o computador, do video game com o mundo do espetáculo, da "auto-estrada da informação"1 e do desejo interminável de renovar as conquistas territoriais. Dessa forma, com Tron, o cinema transformou o homo galactius em homo informaticus, projetando a imagética tecnológica não mais num espaço de extraterrestre, mas num ciberespaço informático que se revelou definitivamente no cinema dos anos $90 \mathrm{em}$ filmes como The Net (Irwin Winkler, 1995) e Matrix (Andy e Larry Warchowski, 1999).

A revolução que provocou a imagem digital tem as suas qualidades técnicas obtidas graças a um cálculo matemático feito pelo homem que transformou os métodos de criação e de linguagem. No entanto, se o instrumento mudou, uma grande parte desse tipo de imagem é obtida pela digitalização de objetos reais, de fotografias de lugares, fazendo com que a problemática continue a mesma: criar uma relação com o mundo. Num filme como Jurassic Park (Steven Spielberg, 1993), as miniaturas dos dinossauros foram criadas a partir de esculturas e, em outros filmes, sobretudo os de animação, essas mesmas miniaturas foram obtidas a partir de imagens feitas em gravuras. A imagem digital é, portanto, híbrida: ela está no lugar de alguma outra coisa (imagem pintada ou esculpida) e, ao mesmo tempo, ela está lá por causa de alguma coisa. Nesse sentido, as novas imagens nos remetem à especificidade do cinema tal como ele foi concebido desde as suas origens, ou seja, como um instrumento capaz de reproduzir o homem e a maneira como ele vive.

O cinema nasceu de preocupações científicas que nos remetem, metaforicamente, à idéia de resistência do corpo à morte. O que faz a imagem digital é perpetuar, de alguma maneira, essa 
idéia a partir da construção que permite ao extremo do imaterial figurar o material por excelência, o que vem a ser a referência comum a todos.

A imagem digital propõe, então, uma sensação do "duplo eterno" que se apresenta como sintoma da luta contra a morte, fixando a mimesis não mais sobre a aparência, mas sobre as idéias e, nesse caso específico, sobre aquela da procura da perfeição. Decompor o real para melhor recompô-lo é no que consiste o trabalho da imagem digital $e$, segundo o cineasta Michelangelo Antonioni, as novas técnicas servem para obter o que já se procurava com os procedimentos tradicionais.

Com o filme Terminator II, Judgement Day (James Cameron, 1991), surpreendemos-nos mais uma vez com o uso da técnica vedete do morphing. Capaz de imitar qualquer forma, o personagem $\mathrm{T}$ 1000 se transforma pela incorporação; ele é polimorfo, diferente, aparentemente, do corpo humano, mas utiliza artifícios que são próprios dos humanos. O filme faz clara referência à dialética da metamorfose e da distorção, remetendo-nos, nesse sentido, à visão de Méliès, que expôs, intuitivamente, os princípios de base do morphing. Com essa técnica, o corpo aparece desfigurado, decomposto, transformado. Nesse caso, a relação que a imagem digital cria com o espectador não é o que ela aparenta; o espectador vê o semelhante através do que não se assemelha. Ou seja, o personagem T-1000 encarna a noção de Bergson e Deleuze de fluxo, ou a imperceptível transformação cotidiana que diz respeito a cada um de nós: o fato de que o homem, mesmo que ele se veja sempre idêntico, está num contínuo processo de mudança.

No começo, o morphing se tornou uma técnica fetiche no mundo do audiovisual, alastrando-se de maneira fulgurante através de reportagens, videoclipes, publicidades, para, em seguida, cair na banalidade. Esse processo pode ser compreendido como um sinal de reivindicação, graças ao digital, de um imaginário próprio, livre do grande fardo do "real" que pesou durante muitos anos sobre o cinema. $O$ digital permite extrair os elementos visíveis do real para transformálos em outra coisa, de maior potência, abrindo caminho para uma nova lógica de artifício que fez filmes mutantes como Who Framed Roger Rabbit? (Robert Zemickis, 1988), The Mask (Charles Russel, 1994) e Being John Malkovitch (Spike Jonze, 1999). Todos esses filmes tratam da precariedade da imagem do corpo e das diversas máscaras que revestem o sujeito na atualidade e suas diferentes identificações.

Não podemos deixar de destacar que a imagem digital nos remete a um certo tipo de cinema, sobretudo aquele realizado pela indústria hollywoodiana que legitima esse tipo de imagem. O cinema de Hollywood encontrou no estilo de filmes de efeitos especiais o espaço de comunhão da técnica com o espectador, um meio de restaurar por um tempo o imaginário do impossível, da ressurreição, do corpo instável e da conquista tecnológica. Méliès concebia o cinema como um parque de diversões em que o ilusionismo típico dos diferentes tipos de truques encantava tanto crianças como adultos. Hollywood seguiu os passos do pai da trucagem, permitindo aos espectadores sentirem o prazer da imagem, mas também da técnica e dos instrumentos cinematográficos.

Por outro lado, um dos maiores sonhos do cinema é o de permitir ao espectador passar para o outro lado da tela. Realizar essa passagem significa para esse espectador entrar na imagem e contar com a possibilidade de existência de um mundo virtual, onde, em princípio, "tudo é possível". Se, ao longo da sua história, vários filmes ilustraram essa experiência, como por exemplo The Purple Rose of Cairo (Woody Allen, 1985) ou Les Carabiniers (Jean-Luc Godard, 1963), tal experiência não se constitui em uma possibilidade "concreta", mesmo que ela possa ser simulada de diferentes maneiras.

Uma dessas maneiras corresponde a um produto derivado de certos filmes: 0 
video game. Certo tipo de filme funciona como uma propaganda na qual o video game se tornou o princípio de execução; esses filmes são concebidos de maneira a permitir sua exploração lúdica interativa. Isso tende a favorecer um cinema voltado para o espetáculo, rico em efeitos especiais e se baseando freqüentemente em histórias suficientemente simples que permitem escolhas claras a cada reviravolta da narrativa.

A simulação de imagens produz no espectador um processo chamado de "imersão", noção que designa, nesse sentido, a maneira pela qual o sujeito mergulha em uma imagem e em um som virtuais criados pelo computador. Esse processo é ativado por certos dispositivos como a projeção de imagens "anamórficas" sobre uma tela gigante ou hemisférica que se constitui hoje como uma atração de shopping centers e parques de diversão em todo o mundo. Esse tipo de espetáculo é herdeiro da fantasmagoria que já era destaque no século XIX e que associava os dispositivos da projeção aos efeitos do roteiro teatral.

Existe ainda um outro dispositivo que compõe o tipo desses filmes de imersão; ele propõe a abolição das salas, pois se constitui em um cinema inteiramente individual. Ele consiste em um fone chamado Eye Phone (Head Mouted Display) e em uma "luva de dados" conhecida como Dataglove. Inventado em 1986 por um americano, Jaron Lanier, tal dispositivo permite a seu usuário (observamos que a noção de espectador perde aqui seu sentido) ficar imerso em um ambiente digital concebido em tempo real, evoluir e agir de acordo com os movimentos da sua cabeça e das suas mãos (analisados por captadores). A imersão interativa, permitida teoricamente por esse fone, tornou-se o grande feito da tecnologia, tendo explodido no microcosmo informático a partir da imagem programada interativa, dos captadores de movimento, do retorno do esforço pelo feedback.
No final de 1988, a Sony colocou no mercado o Glasstron, um cinema portátil composto por um par de óculos que, no lugar das lentes, possui duas telas de cristal líquido cujos aros incorporam os fones à saída de som. Ligadas a um vídeo portátil de Digital Vídeo Disc (DVD), as lentes possibilitam a projeção de filmes sobre telas totalmente virtuais. O DVD portátil foi feito de forma que permite sua conexão a um televisor ou a um computador. Por causa desse dispositivo, o cinema também entrou na era da miniaturização e do portátil (mesmo que seja recomendado ao espectador utilizar sentado os óculos para obter mais conforto), participando, assim, das trocas que fazem parte da sociedade contemporânea, onde tudo se torna cada vez menor para poder ser transportado, permitindo as pessoas se comunicarem em qualquer lugar e, portanto, estabelecerem laços cada vez mais móveis, em um vai-evem característico da atualidade.

Tanto esses fones quanto esses óculos são destinados pelos fabricantes a um público bem específico: os amantes de "novas" tecnologias. No entanto, esses tipos de tecnologia se inserem em um universo marcado pela vontade de superar tudo de forma contínua e por uma euforia de consumação. Porém, sua comercialização não se desenvolveu prontamente. A imersão possível é diferente da imersão sonhada, ou seja, a experiência do sonho, tal qual nós podemos realizar no cinema, tornou-se impossível com essa forma e com essa natureza de dispositivo tecnológico.

No entanto, a fusão do audiovisual e do computador, através do DVD, possui inúmeras qualidades quanto à restituição da imagem e do som, além de permitir ao usuário ir diretamente a qualquer cena do filme, possuindo uma capacidade de mais de oito horas de projeção e propondo uma escolha de línguas, contando ainda, às vezes, com cenas inéditas, making of, diferentes anúncios de filmes e comentários suplementares, além de possibilitar ao cineasta uma liberdade de criação em 
relação à pressão dos distribuidores, já que eles podem realizar uma versão curta da sua obra para salas e outra longa para o DVD. Todo esse atrativo transformou o DVD no mais novo fetiche de consumo, principalmente para os cinéfilos, que podem contar com uma qualidade infinitamente superior da imagem do que aquela oferecida pelas fitas VHS, estabelecendo para um futuro próximo o fim da vida útil dessas fitas, seguindo um processo similar ao que se passou com o disco de vinil (substituído pelo CD).

Além disso, todos os benefícios do DVD, como a utilização concentrada de tudo o que ele pode estocar (que diz respeito ao som, ao vídeo e aos jogos), podem ser usufruídos em um formato de computador cuja multiplicidade de dispositivos permite exercer todas essas funções, fazendo do computador, no século XXI, um instrumento completo.

O cinema também teve penetração na internet, sobretudo através de notícias sobre filmes e festivais, assim como através de publicidade e trocas de informações de todo tipo que dizem respeito ao cinema. Apesar dos rumores em torno de filmes como The Blair Witch Project (Daniel Myrick, 1999), para os quais se propõe a difusão na rede antes da estréia nas salas, o número de entradas aumentou. Se Star Wars, Episode 1: The Phantom Menace (Goerge Lucas, 1999) teve uma difusão pirata na internet, o cinema no computador continua pouco estimulante, e a qualidade deixa a desejar, com uma péssima definição da imagem, tela de tamanho reduzido, além da freqüente imobilização da imagem enquanto o computador está trabalhando.

A indústria hollywoodiana já produziu o primeiro filme destinado exclusivamente ao computador, The Quantum Project (Eugenio Zanetti, 2000), que foi distribuído somente na rede e cobrado para ser carregado. Porém, a produção de programas destinados à internet continua, atualmente, na incerteza. Aquilo que ficou conhecido com o nome de Sillywood, ou seja a aliança entre Sillycom Valley e Hollywood, cujo objetivo era o de realizar programas para a internet, encontra-se em um profundo processo de crise. A falência de algumas empresas que compõem esse conglomerado, como a Pop.com e a Sockwave.com, mostra-nos que a junção entre o cinema e a internet deveria se diversificar ao invés de ver, nessa última, uma maneira a mais de exibir filmes. O sucesso desse tipo de site dependerá da introdução de novos conteúdos interativos, respondendo ao desejo de um público bem específico, mas nunca através da difusão de filmes.

Em contrapartida, a internet se tornou um meio para os iniciantes, que não contam com uma distribuição mais especializada, constituindo-se sobretudo nos filmes realizados por estudantes de cinema, permitindo a difusão desses seus trabalhos e o encontro de um público. A partir dessas experiências e da difusão de anúncios de filmes, é que se pode fazer experiências para testar o máximo de possibilidades técnicas e ver como reagem os internautas.

A internet é, então, um paradoxo para o cinema, ou seja, essa janela de difusão extremamente cortejada, apesar da sua grande capacidade interativa, constituise finalmente em um lugar onde ninguém sabe exatamente o que fazer. Na realidade, a internet consiste em um lugar onde o cinema não pode se desenvolver em sua maneira plena - uma massa desconhecida em uma sala escura vendo juntas imagens projetadas em uma tela grande -, se constituindo em um instrumento para circulação de informações que dizem respeito ao cinema, além de um laboratório para novas experiências.

Essas possibilidades técnicas fazem com que a noção de interatividade seja questionada. Se ela permite ao espectadorusuário intervir no curso de um filme, uma estrutura tão aberta pode acionar um fenômeno de entropia, já que o excesso de 
opções e escolhas pode desestimular a sua utilização. Paradoxalmente, uma narrativa fílmica "rica" deveria cativar o usuário de maneira que ele pudesse apreciar a história inteira antes de usufruir outros caminhos. Os filmes destinados a essa forma de interação ou de imersão tornam mais complexo e difícil o papel do autor do filme, já que precisa reter a atenção do seu público de forma suplementar.

Em suma, o virtual, compreendido aqui no sentido dado por Pierre Lévy, como vetor de uma criação fundada sob uma mudança de identidade da imagem, sem falar dos fones, das luvas ou dos óculos especiais, está em todo lugar: no CDROM, na internet, na animação em tempo real, no home theatre, evoluindo cada vez mais. Mas a potência do sonho e a magia do desejo do imaginário continuam nos levando à fascinação que exerce o cinema tal como ele foi concebido na sua origem, pois é somente dessa forma que possibilita a existência das outras.

Ao mesmo tempo, podemos observar que as "novas" tecnologias são portadoras de vários tipos de transformações para o cinema: estéticas (elas modificam a sensibilidade do espectador em relação ao filme), estruturais (em termos de distribuição e de financiamento) e no que se refere ao consumo de filmes. $O$ digital marcou, assim, o cinema nos últimos anos e deve continuar a fazê-lo por algum tempo. Para pensarmos sobre os seus efeitos, podemos pegar como exemplo o filme que mais se destacou na última década: Titanic (James Cameron, 1998). Seu sucesso planetário é razoavelmente surpreendente, pois se trata de uma ficção que retomou para o cinema a ligação entre a grande aventura e o romanesco, gêneros que havia algum tempo não encantavam o público. Além disso, promoveu uma dissolução do real no corpo do filme, ou seja, com Titanic os efeitos especiais se tornaram invisíveis, fundindo-se na narrativa do filme; os corpos dos atores, como vetores de uma mise-emsceène do "real", absorvem literalmente a tecnologia digital no filme. Isso nos mostra que o público ainda se identifica com uma forma clássica de narrativa e que essa forma pode ser colocada em prática através das novas tecnologias.

Por outro lado, o mundo que espelha alguns filmes hollywoodianos, como Being John Malkovitch e Matrix, funciona segundo regras bem precisas, definidas pelo mestre do jogo invisível, que fazem com que o espectador passe por um processo não mais de identificação ou catártico, mas de adesão plena e definitiva, fazendo com que o cinema se torne, dessa forma, um jogo interativo no qual lhe é cobrado uma participação mais completa possível. Matrix denuncia uma desconfiança ambivalente em relação ao clima virtual em que se concentra a sociedade, porque o filme é, ao mesmo tempo, um produto de alta qualidade do gênero. Fazendo um elogio às teorias do simulacro de Jean Baudrillard, Matrix mostra o real como uma utopia impossível. Mesmo que isso pareça um paradoxo, já que nos coloca de alguma maneira diante de uma tentativa de escapar do simulacro pelo simulacro, a ilusão é alcançada, pois consiste em uma força para criar relações.

Essa digitalização do cinema considera, então, a imagem como dotada de um novo formato por excelência, o que aparece na produção, na filmagem e na pós-produção, fazendo com que a dominação da película sofra uma ameaça simbólica. O procedimento de criação de uma transmissão digital por satélite (criação de um cibercentro, difundindo via satélite filmes digitais em salas equipadas para esse tipo de imagem) poderia levar à supressão da película e da circulação de cópias, facilitando assim o acesso a essas e reduzindo também o custo da distribuição. Por enquanto, pouquíssimas salas no mundo (nenhuma no Brasil) possuem o equipamento adequado para esse tipo de exibição, que continua muito caro, mas é possível que, no futuro, o vídeo digital e o satélite ocupem o lugar da bobina 
e da película, modificando completamente a maneira de fazer cinema.

Por enquanto, o que nos interessa aqui são as vantagens que pode trazer o vídeo digital no que diz respeito sobretudo à redução de custos na produção, o que implica a aparição de um estilo estético particular em adequação com o processo de mutação tecnológica que está em curso atualmente. O polêmico movimento do Dogma 95 pode nos dar a esse respeito algumas pistas de reflexão.

A partir de manifesto elaborado em 1995 por um grupo de cineastas dinamarqueses, impulsionados por Lars von Trier, o Dogma 95 apresenta dez preceitos com o objetivo de regular a atitude dos cineastas (não importando de qual país eles venham) no momento da filmagem. Sob o plano técnico, o manifesto prega a proibição de toda forma de artifício e de jogo com o espaço-tempo (o filme deve se passar aqui e agora); no plano artístico, o movimento é a favor do abandono da noção de autor, o cineasta sendo visto não como o criador de uma obra, mas como o criador de uma seqüência de instantes, tendo cada um deles mais importância que a sua totalidade. ${ }^{2}$

Através de filmes como Festen (Thomas Vinterberg, 1998) e Idioterne (Lars von Trier, 1998) e além, das restrições que caracterizam toda forma de manifesto, o grande feito do Dogma 95 foi a afirmação da sobriedade como potência para estimular o cinema do futuro: sobriedade na narrativa e na maneira de produzir, na direção, na apropriação do movimento, do espaço e dos corpos. Aqui, a imagem digital pode ser vista como um retorno às origens do cinema e, ao mesmo tempo, como um salto no pós-cinema, no cinema eletrônico. Isso é equivalente a realizar, em escala planetária, um cinema feito com « uma camêra na mão e uma idéia na cabeça ", como concebeu Glauber Rocha, preservando ainda a proximidade com os atores. Dessa forma, o Dogma 95 se firma como uma maneira de se opor à espetacularização do cinema e ao mito hollywoodiano.

O vídeo digital nos mostra que a função precede o instrumento, o que nos remete à idéia de Sartre segundo a qual « a compreensão se realiza na imagem e não pela imagem. ${ }^{3}$ Com o digital, é possível fazer qualquer tipo de cinema, - que significa uma mudança na sua estética e não a sua morte, na medida em que o cinema soube tirar proveito dessa tecnologia e se renovar através dela, como mostram alguns filmes exteriores ao Dogma 95, como Dancer in the Dark (Lars von Trier, 2000), La vierge des tueurs (Barbet Schroeder, 2000) e Nationale 7 (Jean-Pierre Sinapi, 2000). Esses filmes representam um cinema atual que junta as pessoas em torno de imagens totalmente digitais. Dancer in the Dark é a encarnação desse cinema pós-moderno: o filme é uma homenagem ao cinema com uma mistura de gêneros, particularmente entre o filme musical e o melodrama; filmado em digital, ele trata de um tema arcaico (a pena de morte) que continua impregnando a atualidade, e que, mesmo assim, continua permitindo aos espectadores estabelecerem identificações plenas de sonho e de imaginação a partir da imagem daquela que vive a personagem interpretada por Björk.

Apesar de todas essas transformações, a questão fundadora do cinema persiste: a estréia dos filmes nas salas. Se para Paul Virilio as novas tecnologias fazem com que o cinema se encontre atualmente em uma "crise do seu lugar, ${ }^{4}$ pois as salas de projeção se opõem a um isolamento do indivíduo diante do seu computador, promovendo, assim, um «acidente cibernético » suscetível de desintegrar o tecido social no seu conjunto, também é possível dizer, em contrapartida, que o que Virilio chama de "crise do lugar » remete-nos a uma diversificação de lugares, já que as salas continuam tendo um papel importante e permitindo o encontro de diversas maneiras entre as pessoas. 
Além disso, é do ritual de freqüentar as salas que depende o sucesso de outras formas de exploração de filmes, como bem demonstrou o advento do videocassete e do cabo. Mesmo se as receitas dos filmes foram transferidas em parte para essas outras formas de exploração, - cinema soube se diversificar para enfrentar essa nova situação. Até mesmo os videos games não estabelecem uma verdadeira concorrência com os filmes; eles correspondem a uma necessidade completamente diferente daquela que possui o público de cinema, pois não participam dos processos de projeção e identificação da mesma maneira que estabelece o espectador com o filme.

Assim, apesar da importância que continuam tendo as salas na exploração cinematográfica, a multiplicidade de formas de difusão provocou cada vez mais o esvaziamento da noção de "grande público", o que praticamente perdeu o seu sentido. O público pode hoje se identificar com diversos tipos de imagens de diferentes maneiras, o que quer dizer que existe toda uma gama de públicos bem específicos e que a distribuição se tornou o elemento essencial que permite atingir todos esses públicos distintos.

A criação cinematográfica atual permite fazer imagens (antigas e novas), levando em conta os riscos da época, ou seja, a multiplicação dos modos de distribuição e exploração. Como disse Edgar Morin, "o imaginário é a prática mágica espontânea do espírito que sonha, ${ }^{5}$ e as novas técnicas cinematográficas advêm das aspirações, dos desejos e dos medos do homem: são seus sentimentos que, segundo sua própria lógica, continuam a organizar todas as ficções. Assim, encontramos filmes que reativam antigas idéias míticas para cristalizá-las através de tecnologias alimentadas por um olhar voltado para o cinema e para a vida, contribuindo para o caráter múltiplo da produção cinematográfica e para a possibilidade de atingir os diferentes gostos.
A experiência do cinema continua viva, e nós a vivemos todos os dias, começando pelo desejo de sair de casa para continuar a dividir emoções com desconhecidos em uma sala escura, mesmo que essa prática tenha se transformado de alguma maneira sob os efeitos das mudanças tecnológicas, pois é o imaginário que continua a atrair as pessoas em direção às imagens cinematográficas .

Notas

1 Consiste em uma rede de fibras óticas com o objetivo de ligar o maior número possível de sites. A internet consiste em um tipo.

2 Para conhecer em detalhes os dez preceitos do Dogma 95, ver V. Pinel, Écoles, genres et mouvements au cinéma, Paris, Larousse, 2000, p. 86.

3 J-P. Sartre, L'imaginaire, Paris, Larousse, 2000, p.86.

4 Ver P. Virilio, "Le bombardement de Nantes ", in Cahiers du cinéma, $n^{0}$ 503, junho 1996.

5 E. Morin, Le cinéma et l'homme imaginaire, Paris, Minuit, 1958, p. 31.

\section{Referências}

AUMONT, Jacques e MARIE, Michel, L'analyse des films, Paris, Nathan, 1988.

BAUDRILLARD, Jean, Simulacres et simulation, Paris, Galilée, 1981.

BAZIN, André, Qu'est-ce que le cinéma ?, Paris, Cerf, 1993.

CASSETI, Francesco, Les théories du cinéma depuis 1945, Paris, Nathan, 1999.

BERGSON, Henri, Matière et mémoire, Paris, PUF, 1997.

DELEUZE, Gilles, L'image-mouvement, Paris, Minuit, 1983.

LÉVY, Pierre, Qu'est-ce que le virtuel ?, Paris, La Découverte, 
1995.

MAFFESOLI, Michel, La contemplation du monde, Paris, Grasset, 1993.

\section{Revistas}

Cahiers du Cinéma, hors-série, novembro de 2001.

Cahiers du Cinéma, hors-série, dezembro de 2001. 